\title{
What strikes most when we think of Geoff
}

\author{
Cinzia Volonté ${ }^{1,2}$ (D)
}

Received: 16 February 2021 / Accepted: 21 February 2021 / Published online: 3 March 2021

(C) The Author(s), under exclusive licence to Springer Nature B.V. 2021

What strikes most when we think of Geoff is his sparkling energy: it not by chance that ATP is pure energy.

However, it doesn't matter what he did for a living, what kind of research he pursued (purinergic signalling for ever and ever), the number of invited lectures that he delivered (remarkably copious), the students that he personally trained (over one hundred), the editorial appointments (over sixty different peerreviewed journals), professional honors (astonishingly numerous) and grants (totaling over £18 million) that he received, or the papers that he published (over fifteen hundred), or the scientists that he inspired (unsurprisingly uncountable).

What amazes most about Geoff is how fully he lived his life, how wisely he searched the intense and deep sense of nature in his art and science, how faithfully he invested in friendly and professional relationships.

For those who didn't have the honor and pleasure of knowing Geoff personally, this is what we will always miss, remember and cherish about Geoff.

\section{Ciao Geoff}

Cinzia Volonté

cinzia.volonte@cnr.it

1 Institute for Systems Analysis and Computer Science “A. Ruberti”, National Research Council (IASI-CNR), Rome, Italy

2 Preclinical Neuroscience, IRCCS Santa Lucia Foundation, Rome, Italy

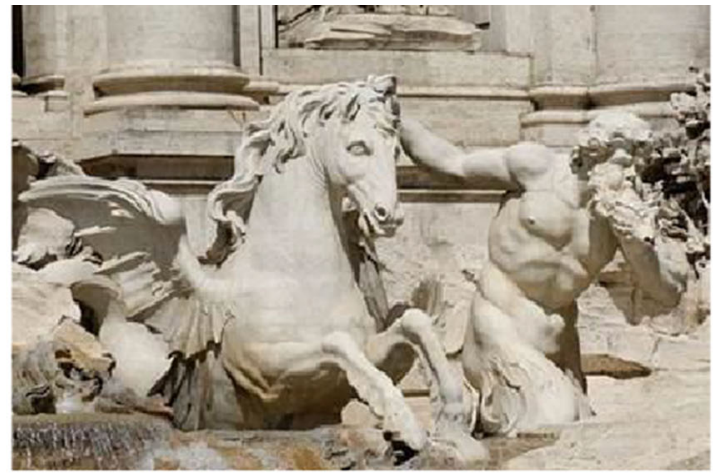

Seventh Joint Italian-German Purine Club Meeting University La Sapienza, Rome, Italy, July 20-22, 2017

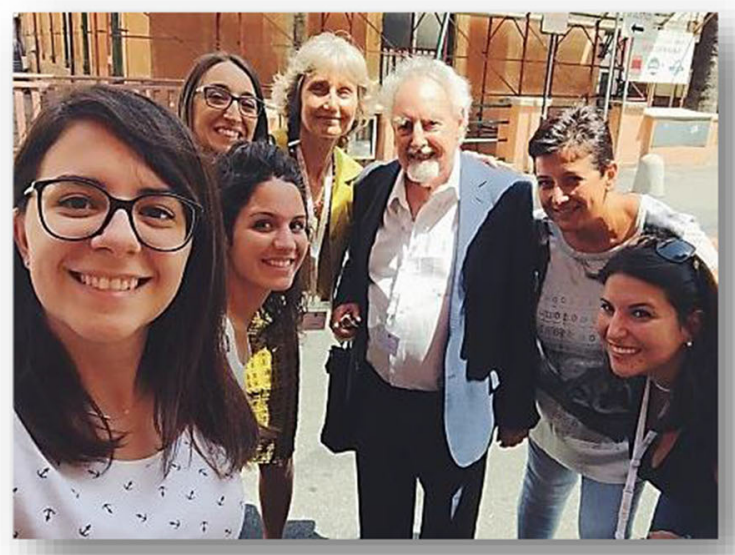

\section{Declarations}

Conflicts of interest Cinzia Volonté declares that she has no conflict of interest.

Ethical approval This article does not contain any studies with human participants or animals performed by any of the authors.

Publisher's note Springer Nature remains neutral with regard to jurisdictional claims in published maps and institutional affiliations. 